Review

\title{
Free light chains: Eclectic multipurpose biomarker
}

\author{
Umberto Basile $^{\mathrm{a}, *}$, Francesca Gulli ${ }^{\mathrm{a}}$, Laura Gragnani ${ }^{\mathrm{b}}$, Cecilia Napodano ${ }^{\mathrm{a}}$, Krizia Pocino ${ }^{\mathrm{a}}$, \\ Gian Ludovico Rapaccini ${ }^{\mathrm{c}}$, Michele Mussap ${ }^{\mathrm{d}}$, Anna Linda Zignego ${ }^{\mathrm{b}}$ \\ a Department of Laboratory Medicine of the Catholic University of Sacred Heart, Rome, Italy \\ b Center for Systemic Manifestations of Hepatitis Viruses (MaSVE), Department of Experimental and Clinical Medicine, University of Florence, Florence, Italy \\ c Institute of Internal Medicine, Catholic University of Sacred Heart, Rome, Italy \\ d Department of Laboratory Medicine, IRCCS-AOU San Martino, Genoa, Italy
}

\section{A R T I C L E I N F O}

\section{Keywords:}

Free light chains

Autoimmune diseases

Rituximab

Immediate hypersensitivity

Viral infections

Multiple sclerosis

\begin{abstract}
A B S T R A C T
The production of antibodies is accompanied by a slight excess of synthesis of $\kappa$ and $\lambda$ immunoglobulin light chains; small amounts of them are released in the peripheral blood and can also be found in various body fluids, such as synovial fluid, cerebrospinal fluid, urine and saliva. They are rapidly filtered by the glomerulus and $>99 \%$ are reabsorbed from the cells of the proximal convoluted tubule, making them present in the urine in only trace amounts. The production of an excess of protein without a reason or a specific function in a biological system is rare. Free light chains, considered for years a waste product of Ig synthesis, are currently known to be very active molecules, able to bind antigens as well as whole immunoglobulin and helping to develop specific antibody affinity. The ability of free light chains to activate mast cells and then become an active part of the pathogenic mechanisms of chronic inflammatory diseases has increased interest in their clinical use, both as an attractive therapeutic target or as a biochemical marker of disease evolution or remission.

This is an overview of relevant scientific interest that immunoglobulin light chains $\kappa$ and $\lambda$ have attracted over the years, a report on the progress in knowledge about their structure and function, with a special focus on their biological meaning and potential clinical utility in different diseases.
\end{abstract}

\section{Introduction}

Immunoglobulin (Ig) free light chains $\kappa$ and $\lambda$ (FLCs) have always been the subject of great scientific interest, and the progress in knowledge about their structure and function have characterized the history of medicine, beginning with Henry Bence Jones (Bence, 1847), Paul Ehrlich (Ehrlich, 1900) and Arne W. Tiselius (Tiselius and Kabat, 1939), who won the Nobel prize in 1948. These early frontrunners were followed by Frank W. Putnam and Ingemar Berggård, who sought the physico-chemical and structural characteristics of FLCs (Putnam and Hardy, 1955; Berggård and Peterson, 1969). The FLC molecular definition is attributable to Gerald M. Edelman (Edelman and Gaily, 1962) and Rodney R. Porter (Porter, 1973). The numerous experimental studies of Alan Solomon (Solomon, 1976) and Karsten Sølling (Sølling and Sølling, 1979) have also played a fundamental role in describing these proteins.
The development of FLCs assays began in the early 1960s and for over 30 years there have been rudimentary semi-quantitative methods, such as simple and radial immunodiffusion (Mancini method) (Mancini et al., 1965), quantitative methods easily practicable but with poor reproducibility, such as the first radio-immunoassays (SøIling, 1975) which were subsequently made more reliable (Robinson et al., 1982), up to the development of non-radioisotope immunological methods, such as immunoassays (Brouwer et al., 1985), turbidimetric (Tillyer et al., 1991). These assays were not considered able to truly determine FLCs, but probably were measuring total (free and bound) light chains. In 2001 an assay for determining plasma FLCs was found, characterized by the use of specific polyclonal antibodies able to selectively bind to the free chains (Bradwell et al., 2001). This technique was subsequently progressively improved (Briand et al., 2010).

Afterwards, a nephelometric assay using a mixture of monoclonal antibodies (Levinson, 1992; Te Velthuis et al., 2011; Pretorius et al.,

\footnotetext{
Abbreviations: pFLCs, polyclonal free light chains; IMWG, International Myeloma Working Group; SMM, smoldering multiple myeloma; mFLCs, monoclonal FLCs; CSF, cerebrum-spinal

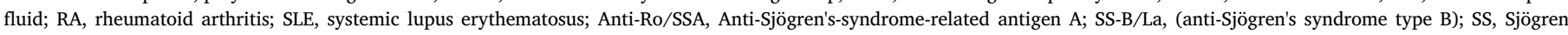

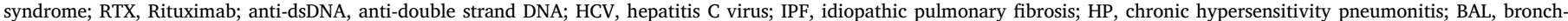

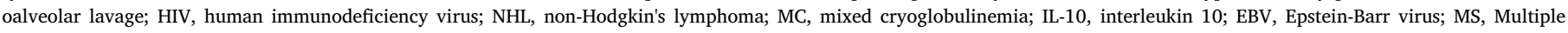
sclerosis; CNS, central nervous system; OB, Oligoclonal immunoglobulins bands; cFLCs, combined polyclonal FLCs; CKD, Chronic Kidney Disease; Ig, Immunoglobulin

* Corresponding author at: Department of Laboratory Medicine of the Catholic University of Sacred Heart, Largo Agostino Gemelli, 8, 00168 Rome, Italy.

E-mail address: umberto.basile@policlinicogemelli.it (U. Basile).
} 


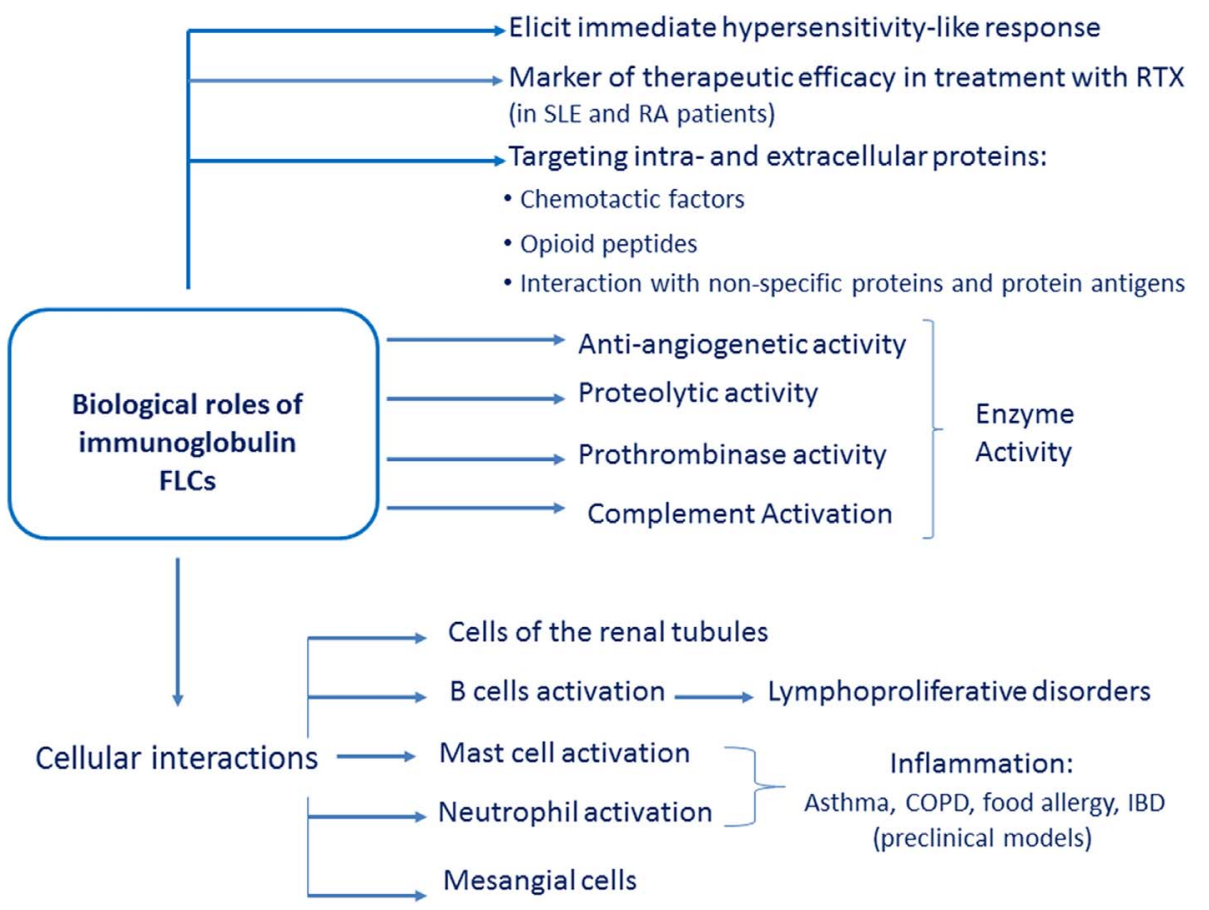

Fig. 1. Biological roles of pFLCs.

2012), multiplex platforms (Campbell et al., 2016) and finally the most recent mass spectrometry (VanDuijn et al., 2015) were applied to FLCs determination. For the first time the International Myeloma Working Group (IMWG) incorporated the FLCs measurement in the 2009 guidelines (Dispenzieri et al., 2009). Since then, numerous guidelines have demonstrated the importance of the FLC assay in the evaluation and monitoring of therapy outcomes, assessment of the prognosis of diseases caused by immunoglobulin deposition and of immune-proliferative disorders (Charafeddine et al., 2012; Graziani and Merlini, 2014). Recently, the IMWG guidelines have highlighted the importance of using an appropriate test for the correct interpretation of the $\kappa / \lambda$ ratio in defining different degrees of smoldering multiple myeloma (SMM) (Rajkumar et al., 2014).

The different forms of molecular aggregation of FLCs, such as monomers, dimers, tetramers, and other polymeric forms (Sølling, 1976), their monoclonal polymorphism, arising from the proliferation of different plasma cell clones, make it difficult to achieve an adequate accurancy for these measurements (Jacobs et al., 2016).

The correlation between two different assays is better for $\kappa$ than $\lambda$ FLC. The two assays are not entirely equivalent. Care should be taken by interpreting physicians and laboratories when considering switching assays (Cigliana et al., 2017).

Until a few years ago, the interest in FLC measurement was confined to the measurement of monoclonal FLCs (mFLCs) for the management of patients with a monoclonal component. The present contribution is dedicated to polyclonal FLCs (pFLCs) and their measurement as a new biomarker for monitoring diseases and treatment of pathologies different from plasma cell dyscrasia.

\section{Expression of pFLCs in the immune response}

Early studies on antibody production, typical of the acquired immune response, showed a slight excess by synthesis of immunoglobulin light chains, giving rise to a release of about $500 \mathrm{mg} /$ day of pFLCs in the peripheral blood (Boivin et al., 2004). pFLCs can also be found in various body fluids, such as synovial fluid, cerebrospinal fluid (CSF), urine and saliva.

pFLCs are rapidly filtered by the glomerulus and $>99 \%$ are reabsorbed from the cells of the proximal convoluted tubule, making them present in the urine in only trace amounts. The production of an excess of protein without a reason or a specific function in a biological system is rare; FLCs should therefore be considered bioactive molecules rather than a secondary product of the synthesis of immunoglobulins (Ig) without any functional relevance. Numerous studies have elucidated the biological role of pFLCs, in the following main functions: enzymatic (including anti-angiogenic activities), $\kappa$ light chain is the first molecule associated with the anti-angiogenic activity of Neovastat, an anti-angiogenic extract from shark cartilage (Boivin et al., 2004); proteolytic, pFLCs displayed hydrolytic activity against inactivated vasoactive intestinal peptide (Sun et al., 1994; Paul et al., 1995); prothrombinase activities, conversion of fibrinogen to fibrin was accelerated by the prothrombin fragments generated by the light chain. These finding suggested a novel mechanism whereby antibodies can induce a pro-coagulant state (Thiagarajan et al., 2000); complement activation, in vitro the $\lambda$ light chain dimer efficiently activates the alternative pathway of complement and represents the first described pathogenic mini-autoantibody in human disease (Jokiranta et al., 1999); specific binding to substrates and enzymes, including protein and non-protein antigens, pFLCs can sensitize mast cells, such that a second encounter with the antigen results in mast-cell activation (Redegeld and Nijkamp, 2003; Van den Beucken et al., 2001); chemotactic factors, X-ray crystallographic techniques showed the binding ways of $\mathrm{N}$-formylated chemotactic peptides to the light chain (BenceJones) dimer (Edmundson and Ely, 1985); Enkephalins and beta-casomorphins (opioid peptides) were found to bind in a variety of conformations to a human light chain dimer from a patient with amyloidosis (Edmundson et al., 1987); binding cells, including mast cells, pFLCs have a crucial role in development of contact sensitivity. Although IgE and IgG are central to the induction of immediate hypersensitivity reactions, these results showed that FLC have a similar activity (Redegeld et al., 2002); in renal tubular cells pFLCs endocytosis leads to production of inflammatory cytokines. This may be an important mechanism of chronic tubule-interstitial inflammation process (Sengul et al., 2002). Experimental studies have delineated important aspects regarding the interactions between glomerulopathic pFLCs and mesangial cells, indicating that these interactions are receptor mediated (Teng et al., 2004); in B lymphocytes were defined a new property of pFLCs that inhibits the autonomous signaling ability of the B-cell 
receptor (Foy and Matsuuchi, 2001; Meixlsperger et al., 2007).

The properties of pFLCs are schematically represented in Fig. 1.

The presence of pFLCs in the circulation is directly related to plasma cell activity: for example, the proliferation of a secreting plasma cell clone causes an increase in mFLCs in serum and other biological fluids (i.e. urine). In this case, the FLCs are identical and monoclonal, only electrophoresis is able to highlight the characteristic monoclonal morphology. However, in many diseases, including those with a decreased kidney filtration rate and chronic inflammatory diseases characterized by B cell activation, pFLCs have been reported to increase, representing a finding of clinical interest (Hutchison and Landgren, 2011). It would be interesting to evaluate the relationship between the pFLCs and the Creactive protein in order to assess the possible relationships between such markers in different chronic inflammatory diseases (Burmeister et al., 2014). The main difference in polyclonal and mFLCs increases is the absence of significant alterations in the $\kappa / \lambda$ ratio. Some diseases are frequently associated with increased pFLCs synthesis in serum, CSF, urine and synovial fluid. FLCs accumulate in the circulation in kidney diseases, and especially in chronic renal damage, due to reduced glomerular filtration rate. pFLC expression was detected in tumor-associated tissues from human breast, pancreas, lung, colon, skin and kidney, while pFLC staining was virtually absent in the corresponding healthy tissue. pFLCs are biomarkers of poor prognosis in basal-like breast cancer and are potential targets in tumor-associated inflammation (Groot Kormelink et al., 2014). pFLCs were co-localized with mast cell infiltrates in tumor tissue leading to the hypothesis that pFLCs can activate mast cells occurring in peri-tumoral inflammation (Groot Kormelink et al., 2014). The clinical significance of pFLCs isotype was studied in a large cohort of patients with breast cancer in a long-term follow-up. Kormelink GT et al. showed that pFLCs expression was associated with an aggressive tumor trait, particularly those with a triplenegative (estrogen receptor, progesterone receptor and HER2 negative) basal-like phenotype (Groot Kormelink et al., 2014). The authors suggested that pFLCs activated mast cells are associated with increased tumor growth in a preclinical tumor model (Groot Kormelink et al., 2014). Increased pFLCs expression in the stroma of breast cancer tissue showed an association with reduced survival. This seems to be evident also in other tumors. Blocking pFLCs with the antagonist F991 could be a novel strategy for therapeutically modifying mast cell-mediated cancer growth (Groot Kormelink et al., 2014).

\section{3. pFLCs and autoimmune diseases}

Autoimmune diseases are characterized by a chronic inflammatory condition. Autoimmunity is an immune system defect of either B or T lymphocytes that are involved in adaptive immune activation. Autoimmune diseases are classified as systemic autoimmune diseases and tissue-specific autoimmune diseases. In this scenario, it is conceivable that the ability of pFLCs to activate mast cells and macrophages play a relevant, yet not fully clarified role.

The first observations of pFLCs alteration in Rheumatoid Arthritis (RA) and Systemic Lupus Erythematosus (SLE) date back to the 1960s; two studies demonstrated that the concentration of pFLCs in serum and urine, was significantly higher compared to healthy controls. This is the first observation correlating the concentration of circulating pFLCs with disease evolution (Epstein and Tan, 1966; Cooper and Bluestone, 1968). Other subsequent studies showed the possibility of pFLCs as biomarkers (Sølling et al., 1981; Jolly et al., 2014; Ye et al., 2013).

A similar study conducted by measuring pFLCs with the Freelite (Binding Site, Birmingham UK) method developed in 2001, confirmed that the concentration of pFLCs is significantly higher in patients with autoimmune diseases than in the normal population, in the absence of a significant alteration of the $\kappa / \lambda$ ratio (Gottenberg et al., 2007). AntiRo/SSA (Anti-Sjögren's-syndrome-related antigen A) antibodies are among the most frequently detected autoantibodies against nuclear antigens and have been associated with SLE and primary and secondary
Sjögren's syndrome (SS). Although the presence of these autoantibodies is one of the criteria for the diagnosis and classification of SS, sometimes, they are also seen in other systemic autoimmune diseases. These antibodies have been used as a useful diagnostic marker for SLE and SS for decades, even if their pathological significance still remains to be clarified. Interestingly, in patients with SS, both primary and secondary to RA, the presence of SS-B/La (anti-Sjögren's syndrome type B) antiextractable nuclear antigens is associated with an increased concentration of serum pFLCs, while this does not occur in patients with SS-A/Ro anti-extractable nuclear antigens. The presence of these autoantigens is a biomarker of the disease, but is not correlated with its clinical course in which increased risk of lymphoma could result from persistent B cell activation and disease activity (Ye et al., 2013). Increased concentration of serum pFLCs and $\beta 2$ microglobulin are markers of disease activity and severity and can be useful for therapeutic monitoring or to assess recurrences after remission (Gottenberg et al., 2013).

Few studies have quantified pFLCs in urine, a non invasive sampling method in patients with different rheumatic diseases. SLE patients have been shown to have an increase of urinary pFLCs in correlation with phases of disease activity and a decrease in quiescent phases (Hopper et al., 2000). Sudden and dramatic increases in urinary pFLCs precede the development of severe clinical manifestations by 4-8 weeks, reflecting activation of B cells (Hopper et al., 1989). However, the results of these studies can be partially affected by the presence of proteinuria, typical in patients with SLE, and by the poor reliability of the analytical methods for the determination of pFLCs in urine. However, more recently, FLCs were measured in plasma of 75 patients with SLE and 41 with RA and the results confirm previous observations obtained in urine samples (Aggarwal et al., 2011) showing that the magnitude of the FLC increase in patients with SLE is clearly correlated with the disease activity. This study also showed that when pFLCs increase, there was no alteration of the $\kappa / \lambda$ ratio, confirming the polyclonal nature of FLCs. These data were confirmed in a recent study where pFLCs in urine were elevated in patients with rheumatic disease, with normal $\kappa / \lambda$ ratio. The correlation between pFLCs and inflammatory markers in patients with RA demonstrates their potential in predicting disease activity (Bramlage et al., 2016). Further studies are required to determine whether FLC assessment could represent a relevant biomarker for response to treatment (especially B cell depletion) and for the risk of lymphoma in autoimmune diseases (Gottenberg et al., 2007). In conclusion increased concentration of pFLCs in SLE and RA subjects could be used as biological markers of disease activity, confirming the interest of pFLCs concentrations in rheumatic disease (Bramlage et al., 2016; Draborg et al., 2016).

\section{4. pFLCs and Rituximab}

The monoclonal anti-CD20 antibody, Rituximab (RTX), is one of the most commonly used drugs in the treatment of RA and SLE, especially in subjects refractory to conventional therapy. RTX acts selectively on CD20-positive B lymphocytes (mature and pre-B cells), leaving the plasma cells almost intact. Monitoring the RTX therapy in patients with SLE and RA is complicated by the lack of effective biochemical markers and the available ones have a low degree of correlation with the concomitant clinical picture. For example, rheumatoid factor and anti-citrulline antibodies usually decrease after RTX treatment, but this does not always indicate an improvement in the patient's clinical condition, making the decision of whether or not to suspend therapy difficult (Mazilu et al., 2014). This scenario explains the lack of consensus regarding the best method for assessing the patient's response to RTX and timing of further treatment (Mazilu et al., 2014). Since the depletion of B cells from peripheral blood reduces the concentrations of serum pFLCs, such information suggests a more effective marker for monitoring patients receiving RTX (Basile et al., 2015).

Recent studies have evaluated the use of pFLCs as a marker of the 
therapeutic efficacy of RTX in patients with SLE and RA and the results seem promising (Chice et al., 2011; Kormelink et al., 2010). Chice's study showed a significant association between the levels of serum $\mathrm{\kappa}$ FLC and the consumption of the C3 complement fraction, that is characteristic of active SLE (Chice et al., 2011). This correlation, never confirmed previously, was described in a preliminary work correlating pFLCs with disease activity (Redegeld et al., 2002). This study demonstrated for the first time that the correlation between serum FLC and complement consumption is preserved even after B cell depletion. The fast turnover of FLCs, particularly of $\kappa$ ones $(<6 \mathrm{~h}$ compared to 20-25 days for total IgG) justified the interest in them as ideal markers of response to RTX. One important result was the presence of a significant correlation between serum pFLCs and IgG, but not between pFLCs and anti-double strand DNA (dsDNA) antibodies, probably because IgG is a marker of polyclonal activation of B cells, while antidsDNA antibodies indicate specific B cell responses. The close monitoring of peripheral repopulation of B lymphocytes and of the levels of anti-dsDNA antibodies was proven to be less useful in the evaluation of SLE relapses. FLC plasma levels monitoring seems to represent a promising tool for a more accurate evaluation of both the disease activity and response to RTX treatment (Chice et al., 2011).

In Kormelink's study (Kormelink et al., 2010) pFLCs were found in high concentrations in the synovial fluid and tissue of affected joints of RA patients treated with RTX and positively correlated with plasma concentrations; furthermore, there was a significant correlation between pFLCs in synovial fluid and acute phase biochemical markers, such as erythrocyte sedimentation rate (ESR) and C-reactive protein. In RA responder patients, B-cell depletion by RTX, 3 and 6 months after initiation of therapy, induced a significant decrease in FLC serum concentrations. However, only in "full responder" patients did FLCs fall within normal ranges, but not always in partial responders, due to the maintenance of local production in synovial tissues.

To confirm the specificity of pFLCs in RA, one study demonstrated that they were present in negligible quantities in the synovial fluid and serum of control patients with osteoarthritis (Burmeister et al., 2014).

pFLC were abundantly present in inflamed joints and their concentrations were correlated with disease activity, suggesting that pFLC were a relevant biomarker for treatment response to rituximab in patient with RA; this seems to confirm the hypothesis that pFLCs reflect the efficacy of RTX and not the severity of the disease (Kormelink et al., 2010).

Interestingly, in contrast to the effect of RTX treatment on serum FLC concentrations, no significant changes were found in serum FLC concentrations 6 and 12 weeks after anti-TNF treatment. This suggests that the changes seen in FLC concentrations after RTX treatment may be part of the therapeutic action of RTX and are not a general feature of clinical response to disease treatment (Kormelink et al., 2010).

Actually, no commercially available assay for FLC determination in synovial fluid has been released yet.

In a retrospective study, pFLCs and their ratio were evaluated in patients with hepatitis $\mathrm{C}$ virus (HCV) related mixed cryoglobulinemia treated with RTX. This study showed that pFLCs and their ratio had predictive value, being important in assessing the patient's response to therapy (Bramlage et al., 2016). Based on all these results, it appears that the determination of pFLCs in association with conventional markers (i.e., rheumatoid factor and anti-citrulline antibodies) could be of clinical utility.

\section{5. pFLCs and immediate hypersensitivity}

The role of pFLCs in the development of non-IgE mediated hypersensitivity reactions has been clarified in the last decade in experimental work on animals and in in vitro studies (Redegeld et al., 2002). When an antigen binds to mast cells, the pFLCs bind themselves to the mast cell-antigen complex, prompting the sensitization of an immunecompetent cell that is activated to release inflammatory mediators (Van den Beucken et al., 2001; Van der Heijden et al., 2006). Ultrastructural analysis of the activated mast cells by pFLCs reveals the presence of large-size granules and the formation of degranulation channels for the fusion of granules themselves (anaphylactic degranulation) (Thio et al., 2008). The action of pFLCs is inhibited by a specific antagonist, the peptide F991 (a peptide fragment of the Tamm-Horsfall protein that acts as a binding site for the FLCs) that selectively blocks the FLCmediated hypersensitivity reaction, while not exercising this type of action in IgE- and IgG1-mediated reactions (van Houwelingen et al,, 2007).

In an animal model study, the administration of F991 in non-atopic asthma completely eliminates airway obstruction and lung inflammation (Kraneveld et al., 2002). In addition, F991 inhibits the infiltration of neutrophils in bronchoalveolar fluid and the development of tracheal hyper-reactivity. There are relatively few clinical studies evaluating the utility of FLC determination in the evaluation of patients with allergic diseases. However, there is evidence that circulating pFLCs significantly increase in subjects with allergic asthma (Kraneveld et al., 2005), allergic and non-allergic rhinitis (Powe et al., 2010), atopic dermatitis (Kayserova et al., 2010), idiopathic pulmonary fibrosis (Groot Kormelink et al., 2011), chronic obstructive pneumonia (Braber et al., 2012) and allergies to milk proteins (Schouten et al., 2010).

pFLCs play an important role in chronic inflammations of the airways: it has been shown that the number of FLC secreting cells is greater in the nasal mucosa of subjects with chronic rhinitis than in controls (Thio et al., 2008). The role of pFLCs in the pathophysiology of allergic asthma is to mediate the antigen-specific response of mast cells; in fact, in a murine model, in vitro and in vivo studies showed that pFLCs induce the activation of mast cells in response to antigenic exposure, and are co-responsible for the clinical symptoms (i.e., exudation of mucous and airway hyper-reactivity). Confirmation of the key role of pFLCs in these diseases derives from the observation that, in an animal model, the intravenous injection of F991 inhibits the mast cells response after sensitization with the antigen (van Houwelingen et al., 2007).

Confirmation of the FLC location on mast cells of the nasal mucosa in allergic and non-allergic chronic rhinitis confirms the hypothesis that pFLCs can promote the extension of the inflammatory phenomenon. In addition, a close association between pFLCs levels and granulocyte mediators (i.e., mast cell tryptase and eosinophil cationic protein) was found, further confirming the involvement of pFLCs in the allergic inflammatory cascade. In allergic and non-allergic rhinitis, the increase in pFLCs similarly occurs for $\kappa$ and $\lambda$ chains and stems from the increased activity of B cells. Analogously with the increase in specific IgE synthesis characterizing allergic syndromes, this leads to the polyclonal synthesis of antigen-specific FLCs. According to the recommendations of the European Academy of Allergy and Clinical Immunology task force, idiopathic rhinitis and non-allergic rhinitis with eosinophilia syndrome, which are FLC-mediated, require a re-classification (Powe et al., 2010). However, it is necessary to identify the antigens that induce an FLC-mediated mucosal response and to conduct further studies to better understand the pathophysiology of non-allergic rhinitis (Johansson et al., 2004).

pFLCs are involved in the early stages of two chronic interstitial lung diseases: idiopathic pulmonary fibrosis (IPF) and chronic hypersensitivity pneumonitis (HP). These are two serious diseases of uncertain etiology and the pathogenetic mechanisms have not yet been completely clarified. pFLCs were measured in serum and BAL of 21 patients with IPF, 22 with HP and 15 healthy subjects (controls), showing significant increases both in serum and in BAL of patients with IPF and HP (Groot Kormelink et al., 2011). The IgG were also increased in patients with HP, while no significant difference was observed for total IgE concentrations in the three groups. However, the mechanism of activation of mast cells in both pathologies is not yet clear. Another striking result has been provided by immunohistochemistry that showed the presence of immunocompetent FLC-secreting cells in the 
lung parenchyma of patients with IPF and HP, but not in the control group. This suggests an active role of pFLCs in the development of these two diseases, probably through a common cascade of activation of the immunological mediators, although the pathogenesis of both diseases is different. Inhibition of pFLCs could prevent the activation of mast cells and inhibit the development of allergy, increasing the potential therapeutic interest of these proteins.

\section{6. pFLCs in viral infections}

The clinical interest in the determination of pFLCs in human immunodeficiency virus (HIV) or hepatitis C virus (HCV) patients comes from the observations about the possible role of their increase as an early biomarker of tumor onset, especially lymphomas (Bibas et al., 2012). In chronic HIV infection, in addition to a progressive loss of CD4 lymphocytes, a series of functional abnormalities of B cells occurs. These are characterized by low levels of antibody against specific pathogens and poor response to vaccines. Paradoxically, the circulating levels of immunoglobulins are high, reflecting a non-specific polyclonal activation of B cells. The result of this B cell disorder is a progressive immunodeficiency which, in turn, constitutes a risk factor for the onset of some tumors, such as non-Hodgkin's lymphoma (NHL) (Engels et al., 2010). In a recent study including $>190$ patients with HIV infection, it was shown that the increase of pFLCs plasma concentration is highly predictive of NHL risk. Moreover, the risk increases in proportion to the concentration of pFLCs (Landgren et al., 2010). This result is especially interesting if we consider that no association between risk of NHL and IgG, IgA and IgM concentrations was found.

The HCV tropism for lymphatic cells (particularly B cells) has been correlated with the development of various autoimmune and/or lymphoproliferative disorders (Zignego et al., 2007; Paroli et al., 2012) of which mixed cryoglobulinemia (MC) is the prototype (Sansonno et al., 2012). HCV patients with MC show a 35-times higher risk of developing lymphoma than the general population (Monti et al., 2005). MC and Bcell non-Hodgkin's lymphoma (B-NHL) are the main extrahepatic manifestations of HCV (Gragnani et al., 2015) and serum levels of pFLCs have recently been used for monitoring them (Oliveira et al., 2014).

The determination of FLCs and the $\kappa / \lambda$ ratio in patients with HCV infection may be clinically useful, especially for predicting the onset of MC. High concentrations of type $\kappa$ FLCs were observed in HCV-positive patients with MC and type II MC (characterized by a monoclonal component that typically uses $\kappa$ light chains) (Terrier et al., 2009). In patients with HCV infection, the alteration in the $\kappa / \lambda$ ratio is positively correlated with the increasing severity of the HCV-related lymphoproliferative disorder, from cryoglobulinemic vasculitis to NHL, and it is an early indicator of the activation of lymphoproliferative mechanisms (Terrier et al., 2009). Finally, it has been observed that the $\kappa / \lambda$ ratio may also be useful in the evaluation of therapeutic efficacy (Basile et al., 2015).

In a murine model, it has been observed that, after inoculation of a myocardiotropic variant of the encephalomyocarditis virus and the subsequent development of viral myocarditis, the synthesis of pFLCs significantly increases, with a consequent increase in their concentration in the circulation (Matsumori et al., 2010). The administration of F991 during the initial period of the infection worsens the clinical picture, suggesting that pFLCs alter the pathogenesis of the disease by exercising both a direct inhibition of viral replication and an indirect anti-inflammatory role. This hypothesis is supported by the observation that the administration of FLCs in mice infected with encephalomyocarditis virus induces the expression of the interleukin 10 (IL-10) gene and interferon $\alpha$ and $\gamma$ which can counteract the viral activity. These studies seem to assign a therapeutic role to FLCs. However, they are preliminary and need to be confirmed.

The association between pFLCs and antibodies against Epstein-Barr virus (EBV) has been analyzed in a recent study of EBV-positive patients with SLE (especially kFLC levels with 69\%). The obtained results showed no correlation between the concentrations of anti-EBV antibodies and those of pFLCs, suggesting that the high concentrations of pFLCs reflected a reactivation of the virus, and the anti-EBV antibodies the extent of a previous infection (Draborg et al., 2016). The concentration of pFLCs correlated with global disease activity scores, reflected inflammation (high CRP and complement consumption) and B cell activity (high dsDNA antibody titers and total IgG and total IgA concentrations) in the SLE patients. The results obtained by this study suggested that the easily quantifiable pFLCs concentrations could be a supplementary serologic biomarker in SLE (Draborg et al., 2016).

\section{7. pFLCs in multiple sclerosis}

Multiple sclerosis (MS) is a chronic inflammatory demyelinating disease characterized by the intrathecal synthesis of oligoclonal immunoglobulins bands (OB), typical of autoimmune inflammatory diseases of the central nervous system (CNS) (Freedman et al., 2005).

Its biological significance relies on the on-site humoral response reflecting altered regulation of B cells segregated in this compartment. The detection of OB in CSF is the only biochemical analysis widely used since late sixties of the last century. Also the assessment of any damage to the blood-brain barrier, through the ratio index measurement of albumin and immunoglobulins in serum and CSF, becomes part of the laboratory diagnostics of MS. In the 1970s some clinical studies had already shown that the disease is characterized by increased pFLCs in the CSF and in urine, particularly the $\kappa$ FLC (Eickhoff et al., 1978; Rudick et al., 1989). At that time, using the determination of pFLCs in the CSF for the diagnosis and evaluation of patients with MS was considered unreliable (Rudick et al., 1985). Subsequently, several studies have evaluated pFLCs in the CSF of MS patients (Lamers et al., 1995; Krakauer et al., 1998), with more recent ones employing new analytical methods (Fischer et al., 2004; Presslauer et al., 2008) showing that pFLCs can be a viable alternative. It has been demonstrated that the absolute concentrations of the $\mathrm{k}$-FLCs are highly sensitive and specific for the diagnosis of clinically isolated syndromes, as well as the relapse and primary progression of MS (Hassan-Smith et al., 2014). One of the advantages of using pFLCs in diagnostics is that the CSF allows FLCs to have a longer half-life here than in plasma $(2-6 \mathrm{~h})$, comparable to that of other proteins. Consequently, changes in CSFFLCs concentration are able to accurately represent even modest increases in pFLCs intrathecal synthesis. This is particularly useful in the early recognition of the evolution to MS of any clinical isolated syndrome such as optic neuritis or brain stem injury. A recent study showed that in patients who have had a clinical isolated syndrome, the increase of CSF-KFLCs was closely related to the risk of evolution of these diseases into MS (Ramsden, 2017).

In this study, the sensitivity and specificity of FLCs were very similar to those of the analysis of oligoclonal bands in the CSF (respectively $90.0 \%$ vs $90.2 \%$ and $82.1 \%$ vs $85.1 \%$ ), but with a lower analytical time and complexity. The normalized multivariate analysis by sex, age and basal lesions detected by brain MRI showed a "hazard ratio" equal to $6.41 \%$ (95\% confidence interval: 1.88 to $21.78 \%$ ). Ultimately, a concentration of $\kappa$-FLC in CSF $>0.53 \mathrm{mg} / \mathrm{L}$ is an independent predictor of conversion of an isolated inflammatory disease into MS (Presslauer et al., 2016).

Whereas FLCs are also present in serum, they are able to passively diffuse into the CSF. FLC CSF/serum quotients are plotted against the $\mathrm{CSF} /$ serum ratio of albumin. Albumin being only synthesized in liver and diffuses just passively into the CSF, the $\mathrm{\kappa FLC}$ Index calculated as $\left[\left(\kappa \mathrm{FLC}_{\mathrm{CSF}} / \mathrm{\kappa FLC}_{\text {serum }}\right) / \mathrm{Q}_{\text {albumin }}\right] \times 1000$ that takes into account the function of the blood-CSF barrier is tentative to increase the diagnostic accuracy of $\kappa F L C$ determination and to better assess the presence of intrathecal immunoglobulin synthesis avoiding false positive (Duranti et al., 2013).

The introduction of technically simple, rapid, quantitative assays for 


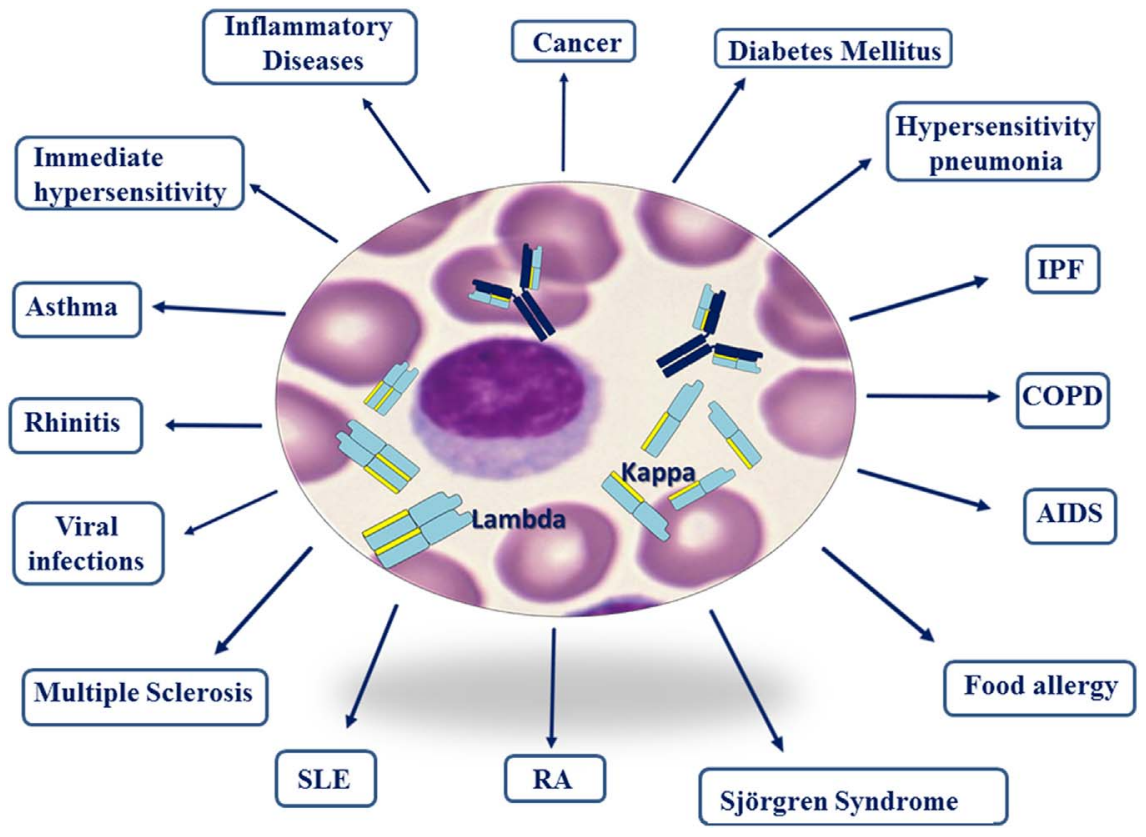

Fig. 2. Diseases where the FLCs may be introduced in clinical practice.

COPD $=$ chronic obstructive pulmonary disease, IPF = idiopathic pulmonary fibrosis, SLE $=$ Systemic Lupus Erythematosus, RA = Rheumatoid Arthritis, AIDS = acquired immune deficiency syndrome. determination of CSF $\kappa$ and $\lambda$ FLC concentrations can replace the technically more difficult, time-consuming, qualitative assay of oligoclonal bands still used in many hospitals for the diagnosis of MS. The possibility of assessing the presence of $\kappa$ FLC monomers or dimers by Western blotting and the combined use of three derived indices related to the molecular shape are able to significantly improve the sensitivity and specificity of FLCs, but this is currently not applicable in daily clinical practice (Kaplan et al., 2013).

\section{8. pFLCs and Chronic Kidney Disease}

FLCs and the kidney are closely related each other. A clear distinction between polyclonal and mFLCs may be useful to better understand the pathogenic role of FLCs in determining renal impairment and damage. Under normal conditions, the synthesis of light chains is slightly unbalanced, originating a small excess of combined pFLCs ( $\mathrm{cFLCs}=\kappa$ FLC plus $\lambda$ FLC) in serum. These cFLCs are readily filtered through the glomerulus and then almost completely reabsorbed by proximal tubular cells after binding to the megalin and cubilin heterodimeric receptor. As a result, only a small amount of polyclonal cFLCs appears in the urine of healthy subjects (Maack et al., 1979). On the other hand, when the production rate of polyclonal cFLCs is markedly increased, the excess of filtered FLCs overwhelms the capacity of the megalin and cubilin receptor to reabsorb these polypetides, and large amounts of cFLCs can be excreted with the urine. In addition, kidney diseases characterized either by the reduction in glomerular filtration rate or by proximal tubular cell impairment lead to the increase in cFLCs serum levels and in cFLCs proteinuria, respectively. The accumulation of pFLCs within the proximal tubule lumen stresses the mechanism of pFLCs endocytosis and induces a cascade of events including: inflammation; activation of redox pathways; transcription of profibrotic cytokines; tubular cells apoptosis, and ultimately the initiation of the epithelial-mesenchymal transition (Basnayake et al., 2011; Liu, 2010). The progression of renal fibrosis induces the reduction in nephron mass that in turn causes an accumulation of pFLCs within the lumen of distal tubules with the formation of proteinaceous casts. These casts are frequently recognized in kidney pathology; they consist of a number of various proteins, including FLCs. Furthermore, polyclonal cFLCs can impair the function of polymorphonuclear granulocytes, namely neutrophils, significantly compromising the immune response. Whether or not FLCs are casually related with the progression of the renal disease is still unclear (Liu, 2010). However, in patients with Chronic Kidney Disease (CKD) a close relationship has been demonstrated between FLCs accumulation and their toxicity in terms of cardiovascular disease (CVD) and mortality (Haynes et al., 2011; Desjardins et al., 2013; Anandram et al., 2012). High serum levels of cFLCs were found strongly associated with mortality in a large secondary care cohort including all non-dialysis CKD stages (Hutchison et al., 2014). In a population with early CKD it was observed a significant relationship between high levels of polyclonal cFLCs and the subsequent mortality risk (Ritchie et al., 2015). Taking into account the hypothesis that systemic inflammation is a relevant contributor to cardiovascular disease (CVD) and mortality in CKD (Assi et al., 2015), this relationship may support the role of polyclonal cFLCs as sensitive biomarkers of systemic inflammation, capable to add prognostic information to conventional acute phase biomarkers, such as high sensitive C-reactive protein. Therefore, serum polyclonal cFLCs may become a sensitive biomarker of adaptive immunity in patients with CKD, especially for assessing subclinical infections, that in turn can determine the survival of CKD patients.

Due to the inverse relationship between serum FLCs levels and renal function, there is the need for separate reference ranges for FLCs in the presence of renal impairment (Hutchison and Landgren, 2011).

There are two nephelometric methods commercially available for the detection of serum FLCs: Freelite (Binding Site, UK) and N Latex (Siemens Healthineers, Germany), which display different results in FLC concentration in CKD patients compared with non-CKD patients, higher in the former group. The parallel increase of both polyclonal $\kappa$ and $\lambda$ FLCs in CKD patients results in the small changes in $\kappa / \lambda$ ratio, for this reason there is no need of adopting different reference limits respect to that used for healthy individuals (Tonelli et al., 2005).

\section{Conclusions}

FLCs, considered for years a waste product of Ig synthesis, are currently known to be very active molecules. FLCs are able to bind antigens as well as whole immunoglobulins, helping to develop specific antibody affinity.

The ability of pFLCs to activate mast cells and become an active part of the pathogenic mechanisms of chronic inflammatory diseases has increased the interest in their clinical use, both as an attractive therapeutic target or as a biochemical marker of disease evolution or 
remission.

The delineation of a patients population with pFLC-induced asthma has a potential therapeutic relevance; in fact, FLC antagonist administration may prevent or ameliorate the adverse manifestation in patients with this often invalidating and occasionally fatal bronchopulmonary disease.

The role of pFLCs in multiple sclerosis is probably the best studied of relevant pathologies, with an important number of diagnostic accuracy studies, therefore $\mathrm{kFLC}$ determination should become a first line screening in the diagnostic algorithms of MS.

In patients with autoimmune or viral diseases, plasma concentration of pFLCs can be considered a biomarker of both disease activity and the effectiveness of RTX treatment, highlighting the key role of pFLCs in chronic inflammatory diseases.

In conclusion, still limited, but very interesting data exist about the clinical utility of pFLC determination in various conditions, strongly suggesting that this biomarker could represent a helpful tool in the clinic, although more well-designed studies are needed before the use of pFLCs can be suggested (Fig. 2). Even if there are no results that show improved clinical outcomes through their monitoring, certainly the use of this biomarker with its interesting physiopathological features could be of additional help in clinical care.

\section{Competing interests}

The authors have no conflicts of interest to disclose.

\section{Funding}

This study received no external funding.

\section{Guarantor}

UB.

\section{References}

Aggarwal, R., Sequeira, W., Kokebie, R., Mikolaitis, R.A., Fogg, L., Finnegan, A., et al, 2011. Serum free light chains as biomarker for systemic lupus erythematus disease activity. Arthritis Care Res. 63, 891-898.

Anandram, S., Assi, L.K., Lovatt, T., Parkes, J., Taylor, J., MacWhannell, A., et al., 2012. Elevated, combined serum free light chain levels and increased mortality: a 5-year follow-up, UK study. J. Clin. Pathol. 65, 1036-1042.

Assi, L.K., McIntyre, N., Fraser, S., Harris, S., Hutchison, C.A., McIntyre, C.W., et al., 2015. The association between polyclonal combined serum free light chain concentration and mortality in individuals with early chronic kidney disease. PLoS One 10 (7), e0129980.

Basile, U., Gragnani, L., Piluso, A., Gulli, F., Urraro, T., Dell'Abate, M.T., et al., 2015. Assessment of free light chains in HCV-positive patients with mixed cryoglobulinaemia vasculitis undergoing rituximab treatment. Liver Int. 35 (9), 2100-2107 (Sep).

Basnayake, K., Stringer, S.J., Hutchison, C.A., Cockwell, P., 2011. The biology of immunoglobulin free light chains and kidney injury. Kidney Int. 79, 1289-1301.

Bence, Jones H., 1847. Papers on chemical pathology: prefaced by the Gulstonian lectures, read at the Royal College of Physicians, 1846. Lancet 50, 88-92.

Berggård, I., Peterson, P.A., 1969. Polymeric forms of free normal kappa and lambda chains of human immunoglobulin. J. Biol. Chem. 244, 4299-4307.

Bibas, M., Trotta, M.P., Cozzi-Lepri, A., Lorenzini, P., Pinnetti, C., Rizzardini, G., et al., 2012. Role of serum free light chains in predicting HIV-associated non-Hodgkin lymphoma and Hodgkin's lymphoma and its correlation with antiretroviral therapy. Am. J. Hematol. 87, 749-753.

Boivin, D., Provençal, M., Gendron, S., Ratel, D., Demeule, M., Gingras, D., et al., 2004. Purification and characterization of a stimulator of plasmin generation from the antiangiogenic agent Neovastat: identification as immunoglobulin kappa light chain. Arch. Biochem. Biophys. 431, 197-206.

Braber, S., Thio, M., Blokhuis, B.R., Henricks, P.A, Koelink, P.J., Groot Kormelink, T, et al., 2012. An association between neutrophils and immunoglobulin free light chains in the pathogenesis of chronic obstructive pulmonary disease. Am. J. Respir. Crit. Care Med. 185, 817-824.

Bradwell, A.R., Carr-Smith, H.D., Mead, G.P., Tang, L.X., Showell, P.J., Drayson, M.T., et al., 2001. Highly sensitive, automated immunoassay for immunoglobulin free light chains in serum and urine. Clin. Chem. 47, 673-680.

Bramlage, C.P., Froelich, B., Wallbach, M., Minguet, J., Grupp, C., Deutsch, C., et al, 2016. The significance and predictive value of free light chains in the urine of patients with chronic inflammatory rheumatic disease. Clin. Rheumatol. 35 (12), 2939-2946.

Briand, P.Y., Decaux, O., Caillon, H., Grosbois, B., Le Treut, A., Guenet, L., 2010. Analytical performance of the serum free light chain assay. Clin. Chem. Lab. Med. 48, 73-79.

Brouwer, J., Otting-van de Ruit, M., Buskung-van der Lely, H., 1985. Estimation of free light chains of immunoglobulins by enzyme immunoassay. Clin. Chim. Acta 150, 267-274.

Burmeister, A., Assi, L.K., Ferro, C.J., Hughes, R.G., Barnett, A.H., Bellary, S., et al., 2014. The relationship between high-sensitivity CRP and polyclonal free light chains as markers of inflammation in chronic disease. Int. J. Lab. Hematol. 36, 415-424.

Campbell, J.P., Heaney, J.L., Shemar, M., Baldwin, D., Griffin, A.E., Oldridge, E., et al., 2016. Development of a rapid and quantitative lateral flow assay for the simultaneous measurement of serum $\kappa$ and $\lambda$ immunoglobulin free light chains (FLC): inception of a new near-patient FLC screening tool. Clin. Chem. Lab. Med (Epub ahead of print 2016 Aug 9). http://dx.doi.org/10.1515/cclm-2016-0194.

Charafeddine, K.M., Jabbour, M.N., Kadi, R.H., Daher, R.T., 2012. Extended use of serum free light chain as a biomarker in lymphoproliferative disorders: a comprehensive review. Am. J. Clin. Pathol. 137, 890-897.

Chice, L., Cournac, J.M., Mancini, J., Bardin, N., Thomas, G., Jean, R., et al., 2011. Normalization of serum free light chains in patients with systemic lupus erythematosus upon rituximab treatment and correlation with biological disease activity. Clin. Rheumatol. 30, 685-689.

Cigliana, G., Gulli, F., Napodano, C., Pocino, K., De Santis, E., Colacicco, L., et al., 2017. Serum free light chain quantitative assays: dilemma of a biomarker. J. Clin. Lab. Anal. http://dx.doi.org/10.1002/jcla.22243.

Cooper, A., Bluestone, R., 1968. Free immunoglobulin light chains in connective tissue diseases. Ann. Rheum. Dis. 27, 537-543.

Desjardins, L., Liabeuf, S., Lenglet, A., Lemke, H.D., Vanholder, R., Choukroun, G., et al., 2013. European Uremic Toxin (EUTox) work group. Association between free light chain levels, and disease progression and mortality in chronic kidney disease. Toxins (Basel). 5, 2058-2073.

Dispenzieri, A., Kyle, R., Merlini, G., Miguel, J.S., Ludwig, H., Hajek, R., et al., 2009. International myeloma working group guidelines for serum-free light chain analysis in multiple myeloma and related disorders. Leukemia 23 (2), 215-224 (Feb).

Draborg, A.H., Lydolph, M.C., Westergaard, M., Olesen Larsen, S., Nielsen, C.T., Duus, K., et al., 2016. Elevated concentrations of serum immunoglobulin free light chains in systemic lupus erythematosus patients in relation to disease activity, inflammatory status, B cell activity and Epstein-Barr virus antibodies. PLoS One 11 (1), e0148151 (Jan 25).

Duranti, F., Pieri, M., Centonze, D., Buttari, F., Bernardini, S., Dessi, M., 2013. Determination of kFLC and K index in cerebrospinal fluid: a valid alternative to assess intrathecal immunoglobulin synthesis. J. Neuroimmunol. 263, 116-120.

Edelman, G.M., Gaily, J.A., 1962. The nature of Bence Jones proteins: chemical similarities to polypeptide chains of myeloma globulins and normal gamma-globulins. J. Exp. Med. 116, 202-227.

Edmundson, A.B., Ely, K.R., 1985. Binding of N-formylated chemotactic peptides in crystals of the mcg light chain dimer: similarities with neutrophil receptors. Mol. Immunol. 22, 463-475.

Edmundson, A.B., Ely, K.R., Herron, J.N., Cheson, B.D., 1987. The binding of opioid peptides to the mcg light chain dimer: flexible keys and adjustable locks. Mol. Immunol. 24, 915-935.

Ehrlich, P., 1900. On immunity with special reference to cell life. Proc. Roy. Soc. London $66,424-448$.

Eickhoff, K., Heipertz, R., Wikström, J., 1978. Determination of k/l immunoglobulin light chain ratios in CSF from patients with multiple sclerosis and other neurological diseases. Acta Neurol. Scand. 57, 385-395.

Engels, E.A., Pfeiffer, R.M., Landgren, O., Moore, R.D., 2010. Immunologic and virologic predictors of AIDS-related non-hodgkin lymphoma in the highly active antiretroviral therapy era. J. Acquir. Immune Defic. Syndr. 54, 78-84.

Epstein, W.V., Tan, M., 1966. Increase of L-chain proteins in the sera of patients with systemic lupus erythematosus and the synovial fluids of patients with peripheral rheumatoid arthritis. Arthritis Rheum. 9, 713-719.

Fischer, C., Arneth, B., Koehler, J., Lotz, J., Lackner, K.J., 2004. Kappa free light chains in cerebrospinal fluid as markers of intrathecal immunoglobulin synthesis. Clin. Chem. 50, 1809-1813.

Foy, S.P., Matsuuchi, L., 2001. Association of B lymphocyte antigen receptor polypeptides with multiple chaperone proteins. Immunol. Lett. 78, 149-160.

Freedman, M.S., Thomson, E.J., Deisenhammer, F., Giovannoni, G., Grimsley, G., Keir, G., et al., 2005. Recommended standard of cerebrospinal fluid analysis in the diagnosis of multiple sclerosis. A consensus statement. Arch. Neurol. 62, 865-870.

Gottenberg, J.E., Aucouturier, F., Goetz, J., Sordet, C., Jahn, I., Busson, M., et al., 2007. Serum immunoglobulin free light chain assessment in rheumatoid arthritis and primary Sjögren syndrome. Ann. Rheum. Dis, 66, 23-27.

Gottenberg, J.E., Seror, R., Miceli-Richard, C., Benessiano, J., Devauchelle-Pensec, V., Dieude, P., et al., 2013. Serum levels of beta2-microglobulin and free light chains of immunoglobulins are associated with systemic disease activity in primary Sjogren's syndrome. Data at the enrollment in the prospective ASSESS cohort. PLoS One 8 (5), e59868.

Gragnani, L., Fognani, E., Piluso, A., Boldrini, B., Urraro, T., Fabbrizzi, A., et al., 2015. Long-term effect of HCV eradication in patients with mixed cryoglobulinemia: a prospective, controlled, open-label, cohort study. Hepatology 61 (4), 1145-1153.

Graziani, M.S., Merlini, G., 2014. Serum free light chain analysis in the diagnosis and management of multiple myeloma and related conditions. Expert. Rev. Mol. Diagn. $14,55-66$.

Groot Kormelink, T., Pardo, A., Knipping, K., Buendía-Roldán, I., García-de-Alba, C., 
Blokhuis, B.R., et al., 2011. Immunoglobulin free light chains are increased in hypersensitivity pneumonitis and idiopathic pulmonary fibrosis. PLoS One 6, e25392.

Groot Kormelink, T., Powe, D.G., Kuijpers, S.A., Abudukelimu, A., Fens, M.H., Pieters, E.H., et al., 2014. Immunoglobulin free light chains are biomarkers of poor prognosis in basal-like breast cancer and are potential targets in tumor-associated inflammation. Oncotarget 5 (10), 3159-3167.

Hassan-Smith, G., Durant, L., Tsentemeidou, A., Assi, L.K., Faint, J.M., Kalra, S., et al., 2014. High sensitivity and specificity of elevated cerebrospinal fluid kappa free light chains in suspected multiple sclerosis. J. Neuroimmunol. 276 (1-2), 175-179 (Nov 15).

Haynes, R., Hutchison, C.A., Emberson, J., Dasgupta, T., Wheeler, D.C., Townend, J.N., et al., 2011. Serum free light chains and the risk of ESRD and death in CKD. Clin. J. Am. Soc. Nephrol. 6, 2829-2837.

Hopper, J.E., Sequeira, W., Martellotto, J., Papagiannes, E., Perna, L., Skosey, J.L., 1989. Clinical relapse in systemic lupus erythematosus: correlation with antecedent elevation of urinary free light chain immunoglobulin. J. Clin. Immunol. 9, 338-350.

Hopper, J.E., Golbus, J., Meyer, C., Ferrer, G.A., 2000. Urine free light chains in SLE: clonal markers of B-cell activity and potential link to in vivo secreted Ig. J. Clin. Immunol. 20, 123-137.

van Houwelingen, A.H., Kaczynska, K., Kraneveld, A.D., Kool, M., Nijkamp, F.P., Redegeld, F.A., 2007. Topical application of F991, an immunoglobulin free light chain antagonist, prevents development of contact sensitivity in mice. Clin. Exp. Allergy 37, 270-275.

Hutchison, C.A., Landgren, O., 2011. Polyclonal immunoglobulin free light chains as a potential biomarker of immune stimulation and inflammation. Clin. Chem. 57, 1387-1389.

Hutchison, C.A., Burmeister, A., Harding, S.J., Basnayake, K., Church, H., Jesky, M.D., et al., 2014. Serum polyclonal immunoglobulin free light chain levels predict mortality in people with chronic kidney disease. Mayo Clin. Proc. 89, 615-622.

Jacobs, J.F., Tate, J.R., Merlini, G., 2016. Is accuracy of serum free light chain measurement achievable? Clin. Chem. Lab. Med. 54 (6), 1021-1030.

Johansson, S.G., Bieber, T., Dahl, R., Friedmann, P.S., Lanier, B.Q., Lockey, R.F., et al., 2004. Revised nomenclature for allergy for global use: report of the nomenclature review Committee of the World Allergy Organization, October 2003. J. Allergy Clin Immunol. 113, 832-836.

Jokiranta, T.S., Solomon, A., Pangburn, M.K., Zipfel, P.F., Meri, S., 1999. Nephritogenic lambda light chain dimer: a unique human miniautoantibody against complement factor H. J. Immunol. 163, 4590-4596.

Jolly, M., Francis, S., Aggarwal, R., Mikolaitis, R., Niewold, T., Chubinskaya, S., et al., 2014. Serum free light chains, interferon-alpha, and interleukins in systemic lupus erythematosus. Lupus 23 (9), 881-888 (Aug).

Kaplan, B., Golderman, S., Yahalom, G., Yeskaraev, R., Ziv, T., Aizenbud, B.M., et al., 2013. Free light chain monomer-dimer patterns in the diagnosis of multiple sclerosis. J. Immunol. Methods 390 (1-2), 74-80 (Apr 30).

Kayserova, J., Capkova, S., Skalicka, A., Vernerova, E., Polouckova, A., Malinova, V., et al., 2010. Serum immunoglobulin free light chains in severe forms of atopic dermatitis. Scand. J. Immunol. 71, 312-316.

Kormelink, T.G., Tekstra, J., Thurlings, R.M., Boumans, M.H., Vos, K., Tak, P.P., et al., 2010. Decrease in immunoglobulin free light chains in patients with rheumatoid arthritis upon rituximab (anti-CD20) treatment correlates with decrease in disease activity. Ann. Rheum. Dis. 69, 2137-2144.

Krakauer, M., Schaldemose Nielsen, H., Jensen, J., Sellebjerg, F., 1998. Intrathecal synthesis of free immunoglobulin light chains in multiple sclerosis. Acta Neurol. Scand. 98, 161-165.

Kraneveld, A.D., van der Kleij, H.P., Kool, M., van Houwelingen, A.H., Weitenberg, A.C., Redegeld, F.A., et al., 2002. Key role for mast cells in nonatopic asthma. J. Immunol. 169, 2044-2053.

Kraneveld, A.D., Kool, M., van Houwelingen, A.H., Roholl, P., Solomon, A., Postma, D.S., et al., 2005. Elicitation of allergic asthma by immunoglobulin free light chains. Proc. Natl. Acad. Sci. U. S. A. 102, 1578-1583.

Lamers, K.J., de Jong, J.G., Jongen, P.J., Kock-Jansen, M.J., Teunesen, M.A., PrudonRosmulder, E.M., 1995. Cerebrospinal fluid free kappa light chains versus IgG findings in neurological disorders: qualitative and quantitative measurements. J. Neuroimmunol. 62, 19-25.

Landgren, O., Goedert, J.J., Rabkin, C.S., Wilson, W.H., Dunleavy, K., Kyle, R.A., et al., 2010. Circulating serum free light chains as predictive markers of AIDS-related lymphoma. J. Clin. Oncol. 28, 773-779.

Levinson, S.S., 1992. Studies of Bence Jones proteins by immunonephelometry. Ann. Clin. Lab. Sci. 22, 100-109.

Liu, Y., 2010. New insights into epithelial-mesenchymal transition in kidney fibrosis. J. Am. Soc. Nephrol. 21, 212-222.

Maack, T., Johnson, V., Kau, S.T., Figueiredo, J., Sigulem, D., 1979. Renal filtration, transport, and metabolism of low-molecular-weight proteins: a review. Kidney Int. $16,251-270$.

Mancini, G., Carbonara, A.O., Heremans, J.F., 1965. Immunological quantitation of antigens by single radial immunodiffusion. Immunochemistry 2, 235-254.

Matsumori, A., Shimada, M., Jie, X., Higuchi, H., Groot Kormelink, T., Redegeld, F.A. 2010. Effects of free immunoglobulin light chains on viral myocarditis. Circ. Res. 106, 1533-1540.

Mazilu, D., Opriş, D., Gainaru, C., Iliuta, M., Apetrei, N., Luca, G., et al., 2014. Monitoring drug and antidrug levels: a rational approach in rheumatoid arthritis patients treated with biologic agents who experience inadequate response while being on a stable biologic treatment. Biomed. Res. Int. 2014, 702701.

Meixlsperger, S., Köhler, F., Wossning, T., Reppel, M., Müschen, M., Jumaa, H., 2007. Conventional light chains inhibit the autonomous signaling capacity of the B cell receptor. Immunity 26, 323-333.
Monti, G., Pioltelli, P., Saccardo, F., Campanini, M., Candela, M., Cavallero, G., et al., 2005. Incidence and characteristics of non-Hodgkin lymphomas in a multicenter case file of patients with hepatitis C virus-related symptomatic mixed cryoglobulinemias. Arch. Intern. Med. 165, 101-105.

Oliveira, I.S., Cabral, M.S., Jesus, L.S., Paraná, R., Atta, A.M., Sousa Atta, M.L., 2014. Serum levels of immunoglobulin free light chains in patients with chronic hepatitis C presenting cryoglobulinemia. Braz. J. Infect. Dis. 18 (6), 638-642 (Nov-Dec).

Paroli, M., Iannucci, G., Accapezzato, D., 2012. Hepatitis C virus infection and autoimmune diseases. Int. J. Gen. Med. 5, 903-907.

Paul, S., Li, L., Kalaga, R., Wilkins-Stevens, P., Stevens, F.J., Solomon, A., 1995. Natural catalytic antibodies: peptide-hydrolyzing activities of Bence Jones proteins and VL fragment. J. Biol. Chem. 270, 15257-15261.

Porter, R.R., 1973. Structural studies of immunoglobulins. Science 180 (4087), 713-716.

Powe, D.G., Groot Kormelink, T., Sisson, M., Blokhuis, B.J., Kramer, M.F., Jones, N.S. et al., 2010. Evidence for the involvement of free light chain immunoglobulins in allergic and nonallergic rhinitis. J. Allergy Clin. Immunol. 125, 139-145.

Presslauer, S., Milosavljevic, D., Brücke, T., Bayer, P., Hübl, W., 2008. Elevated levels of kappa free light chains in CSF support the diagnosis of multiple sclerosis. J. Neurol. 255, 1508-1514.

Presslauer, S., Milosavljevic, D., Huebl, W., Aboulenein-Djamshidian, F., Krugluger, W., Deisenhammer, F., et al., 2016. Validation of kappa free light chains as a diagnostic biomarker in multiple sclerosis and clinically isolated syndrome: a multicenter study. Mult. Scler. 22 (4), 502-510 (Apr).

Pretorius, C.J., Klingberg, S., Tate, J., Wilgen, U., Ungerer, J.P., 2012. Evaluation of the N latex FLC free light chain assay on the Siemens BN analyser: precision, agreement, linearity and variation between reagent lots. Ann. Clin. Biochem. 49, 450-455.

Putnam, F.W., Hardy, S., 1955. Proteins in multiple myeloma. III. Origin of Bence Jones protein. J. Biol. Chem. 212, 361-369.

Rajkumar, S.V., Dimopoulos, M.A., Palumbo, A., Blade, J., Merlini, G., Mateos, M.V., et al., 2014. International myeloma working group updated criteria for the diagnosis of multiple myeloma. Lancet Oncol. 15, 538-548.

Ramsden, D.B., 2017. Multiple sclerosis: assay of free immunoglobulin light chains. Ann. Clin. Biochem. 54 (1), 5-13.

Redegeld, F.A., Nijkamp, F.P., 2003. Immunoglobulin free light chains and mast cells: pivotal role in T-cell-mediated immune reactions? Trends Immunol. 24, 181-185.

Redegeld, F.A., van der Heijden, M.W., Kool, M., Heijdra, B.M., Garssen, J., Kraneveld, A.D., et al., 2002. Immunoglobulin-free light chains elicit immediate hypersensitivity-like responses. Nat. Med. 8, 694-701.

Ritchie, J., Assi, L.K., Burmeister, A., Hoefield, R., Cockwell, P., Kalra, P.A., 2015. Association of Serum Ig Free Light Chains with mortality and ESRD among patients with nondialysis-dependent CKD. Clin. J. Am. Soc. Nephrol. 10, 740-749.

Robinson, E.L., Gowland, E., Ward, I.D., Scarffe, J.H., 1982. Radioimmunoassay of free light chains of immunoglobulins in urine. Clin. Chem. 28, 2254-2258.

Rudick, R.A., Peter, D.R., Bidlack, J.M., Knutson, D.W., 1985. Multiple sclerosis: free light chains in cerebrospinal fluid. Neurology 35, 1443-1449.

Rudick, R.A., French, C.A., Breton, D., Williams, G.W., 1989. Relative diagnostic value of cerebrospinal fluid kappa chains in MS: comparison with other immunoglobulin tests. Neurology 39, 964-968.

Sansonno, D., Russi, S., Conteduca, V., Sansonno, L., 2012. B-cell frequency in HCV-related mixed cryoglobulinemia. Hepatology 58 (1), 448 (Oct 30).

Schouten, B., van Esch, B.C., van Thuijl, A.O., Blokhuis, B.R., Groot Kormelink, T., Hofman, G.A., et al., 2010. Contribution of IgE and immunoglobulin free light chain in the allergic reaction to cow's milk proteins. J. Allergy Clin. Immunol. 125, 1308-1314.

Sengul, S., Zwizinski, C., Simon, E.E., Kapasi, A., Singhal, P.C., Batuman, V., 2002. Endocytosis of light chains induces cytokines through activation of NF-kappaB in human proximal tubule cells. Kidney Int. 62, 1977-1988.

SøIling, K., 1975. Free light chains of immunoglobulins in normal serum and urine determined by radioimmunoassay. Scand. J. Clin. Lab. Invest. 35, 407-412.

Sølling, K., 1976. Polymeric forms of free light chains in serum from normal individuals and from patients with renal diseases. Scand. J. Clin. Lab. Invest. 36, 447-452.

Sølling, J., Sølling, K., 1979. Free light chains of immunoglobulins in amyloidosis. Acta Med Scand 206, 283-287.

Sølling, K., Sølling, J., Rømer, F.K., 1981. Free light chains of immunoglobulins in serum from patients with rheumatoid arthritis, sarcoidosis, chronic infections and pulmonary cancer. Acta Med. Scand. 209, 473-477.

Solomon, A., 1976. Bence Jones proteins and light chains of immunoglobulins (first of two parts). N. Engl. J. Med. 294, 17-23.

Sun, M., Gao, Q.S., Li, L., Paul, S., 1994. Proteolytic activity of an antibody light chain. J. Immunol. 153, 5121-5126.

Te Velthuis, H., Knop, I., Stam, P., van den Broek, M., Bos, H.K., Hol, S., 2011. N latex FLC - new monoclonal high performance assays for the determination of free light chain kappa and lambda. Clin. Chem. Lab. Med. 49, 1323-1332.

Teng, J., Russell, W.J., Gu, X., Cardelli, J., Jones, M.L., Herrera, G.A., 2004. Different types of glomerulopathic light chains interact with mesangial cells using a common receptor but exhibit different intracellular trafficking patterns. Lab. Investig. 84, $440-451$.

Terrier, B., Sene, D., Saadoun, D., Ghillani-Dalbin, P., Thibault, V., Delluc, A., et al., 2009 Serum free light chain assessment in hepatitis $C$ virus-related lymphoproliferative disorders. Ann. Rheum. Dis. 68, 89-93.

Thiagarajan, P., Dannenbring, R., Matsuura, K., Tramontano, A., Gololobov, G., Paul, S., 2000. Monoclonal antibody light chain with prothrombinase activity. Biochemistry 39, 6459-6465.

Thio, M., Blokhuis, B.R., Nijkamp, F.P., Redegeld, F.A., 2008. Free immunoglobulin light chains: a novel target in the therapy of inflammatory diseases. Trends Pharmacol. Sci. 29, 170-174. 
Tillyer, C.R., Iqbal, J., Raymond, J., Gore, M., Mc Ilwain, T.J., 1991. Immunoturbidimetric assay for estimating free light chains of immunoglobulins in urine and serum. J. Clin. Pathol. 44, 466-471.

Tiselius, A., Kabat, E.A., 1939. An electrophoretic study of immune sera and purified antibody preparations. J. Exp. Med. 69, 119-131.

Tonelli, M., Sacks, F., Pfeffer, M., Jhangri, G.S., Curhan, G., 2005. Biomarkers of inflammation and progression of chronic kidney disease. Kidney Int. 68, 237-245.

Van den Beucken, T., Van Neer, N., Sablon, E., Desmet, J., Celis, L., Hoogenboom, H.R. et al., 2001. Building novel binding ligands to B7.1 and B7.2 based on human antibody single variable light chain domains. J. Mol. Biol. 310, 591-601.

Van der Heijden, M., Kraneveld, A., Redegeld, F., 2006. Free immunoglobulin light chains as target in the treatment of chronic inflammatory diseases. Eur. J. Pharmacol. 533, 319-326.

VanDuijn, M.M., Jacobs, J.F., Wevers, R.A., Engelke, U.F., Joosten, I., Luider, T.M., 2015 Quantitative measurement of immunoglobulins and free light chains using mass spectrometry. Anal. Chem. 87 (16), 8268-8274 (Aug 18).

Ye, Y., Li, S.L., Xie, M., Jiang, P., Liu, K.G., Li, Y.J., 2013. Judging disease activity in rheumatoid arthritis by serum free kappa and lambda light chain levels. Kaohsiung J. Med. Sci. 29 (10), 547-553 (Oct).

Zignego, A.L., Giannini, C., Ferri, C., 2007. Hepatitis C virus-related lymphoproliferative disorders: an overview. World J. Gastroenterol. 13, 2467-2478. 